\title{
SARS CoV-2 Genomic Characteristics and Clinical Impact of SARS-CoV-2 Viral Diversity in Critically III COVID-19 Patients: A Prospective Multicenter Cohort Study
}

\section{Slim Fourati \\ Hôpitaux Universitaires Henri-Mondor}

\section{Etienne Audureau}

Hôpitaux Universitaires Henri-Mondor

\section{Romain Arrestier}

Hôpitaux Universitaires Henri-Mondor

\section{Stéphane Marot}

Hôpital Pitié-Salpêtrière, Sorbonne Université,

\section{Claire Dubois}

Hôpital Universitaire Saint-Antoine

\section{Guillaume Voiriot}

Hôpital Tenon, Assistance Publique - Hôpitaux de Paris

\section{Charles-Edouard Luyt}

Hôpital Pitié-Salpêtrière, Sorbonne Université,

\section{Tomas Urbina}

Hôpital Universitaire Saint-Antoine

Julien Mayaux

Hôpital Pitié-Salpêtrière, Sorbonne Université,

\section{Anne-Marie Roque-Afonso}

Hôpital Paul Brousse, Assistance Publique - Hôpitaux de Paris

\section{Tai Pham}

Assistance Publique - Hôpitaux de Paris, Hôpital de Bicêtre

\section{Luce Landraud}

Hôpital Louis Mourier, Assistance Publique - Hôpitaux de Paris, Colombes

\section{Benoit Visseaux}

Hôpital Bichat-Claude Bernard, Assistance Publique - Hôpitaux de Paris

\section{Damien Roux}

Hôpital Louis Mourier, Assistance Publique - Hôpitaux de Paris, Colombes

\section{Raphael Bellaiche}

Hôpitaux Universitaires Henri-Mondor

\section{Anne-Sophie L'honneur}

Hôpital Cochin, Assistance Publique - Hôpitaux de Paris

\section{Zakaria Ait Hamou}

Hôpital Cochin, Assistance Publique - Hôpitaux de Paris

\section{Ségolène Brichler}


Hôpital Avicenne, Assistance Publique - Hôpitaux de Paris

\section{Stéphane Gaudry}

Hôpital Avicenne, Assistance Publique - Hôpitaux de Paris

\section{Maud Salmona}

Hôpital Saint-Louis, Assistance Publique - Hôpitaux de Paris

\section{Raphaël Clere-Jehl}

Hôpital Saint-Louis, Assistance Publique - Hôpitaux de Paris

\section{Elie Azoulay}

Hôpital Saint-Louis, Assistance Publique - Hôpitaux de Paris

\section{Laurence Morand Joubert}

Hôpital Universitaire Saint-Antoine

\section{Anne-Geneviève Marcelin}

Hôpital Pitié-Salpêtrière, Sorbonne Université,

\section{Marie-Laure Chaix}

Hôpital Saint-Louis, Assistance Publique - Hôpitaux de Paris

\section{Diane Descamps}

Hôpital Bichat-Claude Bernard, Assistance Publique - Hôpitaux de Paris

\section{Armand Mekontso Dessap}

Hôpitaux Universitaires Henri-Mondor

\section{Christophe Rodriguez}

Hôpitaux Universitaires Henri-Mondor

Jean-Michel Pawlotsky

Hôpitaux Universitaires Henri-Mondor

Nicolas de Prost ( $\nabla$ nicolas.de-prost@aphp.fr )

Hôpitaux Universitaires Henri-Mondor

\section{Research Article}

Keywords: COVID-19, SARS-Co-V, Variant of concern, Acute Respiratory Failure, Intensive Care Unit

Posted Date: January 6th, 2022

DOI: https://doi.org/10.21203/rs.3.rs-1229021/v1

License: (c) (i) This work is licensed under a Creative Commons Attribution 4.0 International License. Read Full License 


\section{Abstract}

Background: SARS-CoV-2 variant of concern (VOC) a spread worldwide, including in France, at the beginning of 2021. This variant was suggested to be associated with a higher risk of mortality than other variants. Little information is available in the subset of patients with severe disease admitted in the intensive care unit (ICU). We aimed to characterize the genetic diversity of SARS-CoV-2 variants isolated from patients with severe COVID-19 in order to unravel the relationships between specific viral mutations/mutational patterns and clinical outcomes.

Methods: Prospective multicentre observational cohort study. Patients aged $\geq 18$ years admitted in 11 ICUs from Great Paris area hospitals between October 1, 2020, and May 30, 2021 (before the introduction of VOC $\delta$ (B.617.2) in France) for acute respiratory failure (SpO2 $\leq 90 \%$ and need for supplemental oxygen or ventilator support) were included. SARS-CoV-2 infection, determined by RT-PCR testing. The primary clinical endpoint was day-28 mortality. Full-length SARS-CoV-2 genomes were sequenced by means of next-generation sequencing (Illumina COVIDSeq).

Results: 413 patients were included, 183 (44.3\%) had been infected with pre-existing variants, 197 (47.7\%) with variant a (B.1.1.7), and 33 (8.0\%) with other variants. Patients infected with pre-existing variants were significantly older $(64.9 \pm 11.9$ vs $60.5 \pm 11.8$ years; $p=0.0005)$; they had significantly more frequent COPD $(11.5 \%(n=21 / 183)$ vs $4.1 \%(n=8 / 197) ; p=0.009)$, and higher SOFA score (4 [3-8] vs 3 [2-4]; 0.0002). Day-28 mortality was not different between patients infected with pre-existing, a (B.1.1.7) or other variants $(31.1 \%(n=57 / 183)$ vs $26.2 \%(n=51 / 197)$ vs $30.3 \%(n=10 / 33)$, respectively; $p=0.550)$. There was no association between day-28 mortality with a specific variant or the presence of specific mutations in SARS CoV-2 genome, including 17 mutations selected in the spike protein and all 1017 non-synonymous mutations detected throughout the entire viral genome.

Conclusions: At ICU admission, patients infected with pre-existing variants had a different clinical presentation from those infected with variant a (B.1.1.7) and other variants later in the course of the pandemic, but mortality did not differ between these groups. There was no association between a specific variant or SARS CoV-2 genome mutational pattern and day-28 mortality.

\section{Background}

As SARS-CoV-2 evolves and new variants continuously emerge worldwide, sustained monitoring and rapid assessment of genetic changes are required to inform the public health response and health-care management of COVID-19. Since the fall of 2020, the emergence of so-called SARS-CoV-2 "variants of concern" (VOC) and of several "variants of interest" (VOI) appears to result from the adaptation of the virus, combined with strong selective pressures on viral spreading in the context of ongoing collective immunization [1]. Many of the substitutions selected so far are located in the Spike (S) protein, the protein involved in viral attachment and entry into cells and the target of neutralizing antibodies.

SARS-CoV-2 VOC bearing multiple signature (lineage defining) deletions and amino-acid substitutions, such as N501Y and/or E484K (variants a (B.1.1.7), $\beta$ (B.1.351) and $Y$ (P.1)) have spread worldwide, including in France, in early 2021 and onwards. These changes have been suggested to result in increased infectivity, with $50-74 \%$

increased transmissibility for VOC a (B.1.1.7). More recently, variant $\delta$ (B.1.617.2) carrying L452R, T478K and P681R substitutions, with enhanced transmissibility compared to other VOC, has spread and replaced most circulating variants in many parts of the world. Beyond transmissibility and immune evasion, the viral factors that explain the severity of infection and the corresponding case-fatality rate in some patients remain unclear. Mutations located outside of the Spike gene in the SARS-CoV-2 genome have been suggested to contribute to enhanced virulence, but 
these results have not been confirmed in other studies [2-4]. Similarly, the specific role of each VOC in the severity of the disease remains debated. In a preclinical Syrian golden hamster model, animals infected with variant a (B.1.1.7) produced significantly higher levels of proinflammatory cytokines than those infected with other variants, but there was no evidence for an altered phenotype [5]. In clinical settings, preliminary analyses of prognosis in patients infected with variant a (B.1.1.7) have suggested that this variant could be associated with a higher risk of mortality compared with infection with other variants [6,7]. By contrast, other studies found no association between mortality and infection with variant a (B.1.1.7) in patients admitted to hospital [8]. Very few clinical studies have evaluated whether being infected with VOC and VOI could modify the prognosis in the subset of patients with severe disease admitted in the intensive care unit (ICU) [9].

Most of prognostic studies describing the role of VOC compared to pre-existing variants were based on PCR-based screening tests, such as S-gene molecular diagnostic assay failure (SGTF) for variant a (B.1.1.7) $[6,9,10]$, which did not discriminate different variants sharing the same pattern of mutations and could not evaluate the association of mutational hotspots with clinical outcomes. Genomic surveillance by means of full-length viral genome sequencing has become critical to identify circulating variants and the evolution of SARS-CoV-2 genomes over time. Different variants, including VOC and VOI circulate at the same time and their effects on disease severity and on the prognosis of severe forms remain unknown. At a mutational level, the presence of a single substitution (e.g, E484K) or a panel of mutations/deletions could specifically modulate the immune response, with a potential impact on the clinical course of the disease [11].

In this study, we aimed to characterize the genetic diversity of SARS-CoV-2 variants involved in severe COVID-19 cases, in a population of patients hospitalized in ICUs for acute respiratory failure following severe SARS-CoV-2 infection between October 2020 and May 2021, i.e., before the emergence and spread of variant $\delta$ (B.617.2) in France. We further aimed to unravel the relationships between specific viral mutations/mutational patterns and the clinical outcomes of COVID-19 in these patients.

\section{Patients And Methods}

\section{Study design and patients}

This is a prospective multicentre observational cohort study. Patients admitted between October 1, 2020 (week 40/20) and May 30, 2021 (week 21/21) in one of the 11 participating ICUs from the Great Paris area hospitals and included in the ANTICOV study (NCT04733105) were eligible for study inclusion. Inclusion criteria were as follows : age $\geq 18$ years, SARS-CoV-2 infection confirmed by a positive reverse transcriptase-polymerase chain reaction (RTPCR), patient admitted in the ICU for acute respiratory failure (SpO2 $\leq 90 \%$ and need for supplemental oxygen or any kind of ventilator support), patient or next of keen informed of study inclusion. Patients with SARS-CoV-2 infection but no acute respiratory failure or with a PCR cycle threshold (Ct) >32 in nasopharyngeal samples were not included

in the study. The study was approved by the Comité de Protection des Personnes Nord-Ouest IV ( $N^{\circ}$ EudraCT/ID-RCB : 2020-A03009-30). Informed consent was obtained from all patients or their relatives.

Demographics, clinical and laboratory variables were recorded upon ICU admission and during ICU stay. Patients' frailty was assessed using the Clinical Frailty Scale [12]. The severity of the disease upon ICU admission was assessed using the World Health Organization (WHO) 10-point ordinal scale [13], the sequential organ failure assessment (SOFA [14]) score, and the simplified acute physiology score (SAPS) II score [15]. Acute respiratory distress syndrome (ARDS) was defined according to the Berlin definition [16]. The primary clinical endpoint of the study was day-28 mortality. 


\section{SARS-CoV-2 genome sequence analysis}

The full-length SARS-CoV-2 genomes from all included patients were sequenced by means of next-generation sequencing. Briefly, viral RNA was extracted from nasopharyngeal swabs in viral transport medium using NucliSENS $\circledast$ easyMAG kit on EMAG device (bioMérieux, Marcy-l'Étoile, France). Sequencing was performed with the Illumina COVIDSeq Test (Illumina, San Diego, California), that uses 98-target multiplex amplifications along the full SARS-CoV-2 genome. The libraries were sequenced with NextSeq 500/550 High Output Kit v2.5 (75 Cycles) on a NextSeq 500 device (Illumina). The sequences were demultiplexed and assembled as full-length genomes by means of the DRAGEN COVIDSeq Test Pipeline on a local DRAGEN server (Illumina). Lineages and clades were interpreted using Pangolin and NextClade, before being submitted to the GISAID database (https://www.gisaid.org). Phylogeny was performed after full-length genome alignment with Muscle v3.8.31 (maximum-likelihood model GTR+1; 1000 bootstrap replicates), by means of IQ-Tree v1.3.11.1 and iTOL.

\section{Statistical Analysis}

Descriptive results are presented as means ( \pm standard deviation [SD]) or medians ( $1^{\text {st }}-3^{\text {rd }}$ tertiles) for continuous variables, and as numbers with percentages for categorical variables. Two-tailed p-values $<0.05$ were considered statistically significant. Unadjusted comparisons between the main variants were performed using ANOVA or Kruskal-Wallis tests for global comparisons of continuous variables, and $\mathrm{Chi}^{2}$ or Fisher's exact tests for categorical variables, as appropriate. In case of global significance, post-hoc pairwise comparisons were performed using ttests or Mann-Whitney tests for continuous variables, and $\mathrm{Chi}^{2}$ or Fisher's exact tests for categorical variables, as appropriate, applying a Sidak correction to account for multiple testing. Adjusted analyses of the association between variants or mutations and 28- and 90-day mortality relied on logistic regression models, systematically adjusting for age, SOFA score at admission, gender and dexamethasone treatment, computing adjusted odds ratios (ORa) along with their $95 \%$ confidence intervals. Analyses were performed using Stata V16.0 statistical software (StataCorp, College Station, TX, USA), and R 3.6.3 (R Foundation for Statistical Computing, Vienna, Austria).

\section{Results}

Between October 1, 2020, and May 30, 2021, 845 patients were admitted in one of the 11 participating ICUs. Among them, 737 had at least one positive SARS-CoV-2 RNA RT-PCR performed in a nasopharyngeal swab sample in the hospital; 413 patients with a $\mathrm{Ct} \leq 32$ and a nasopharyngeal sample conserved at $-80^{\circ} \mathrm{C}$ that could be used for fulllength viral genome sequence analysis were included in this study. Among these 413 patients, $183(44.3 \%)$ had been infected with so-called "pre-existing" variants, i.e., variants circulating before the emergence of variant a, 197 (47.7\%) with variant $\alpha$ (B.1.1.7), and 33 (8.0\%) with other variants, including $\beta$ (B.1.351) $(n=19,4.6 \%), Y$ (P.1) $(n=2$, $0.5 \%)$ and other variants of interest $(n=12,2.9 \%)$. Figure 1 illustrates the time course of emerging SARS-CoV-2 variants during the study period. Variant a (B.1.1.7) was first detected during the last week of 2020 in $11.1 \%$ of patients, became predominant during the fourth week of January 2021 (51.9\% of patients) and remained so until the last week of May ( $100 \%$ of patients) that corresponded to the end of the inclusion period.

\section{SARS-CoV-2 variant association with clinical phenotypes at ICU admission}

Patients infected with pre-existing variants were older and had significantly more frequent chronic kidney disease and COPD than those infected with other variants (Table 1). Other comorbidities, including diabetes, peripheral vascular disease, solid cancer, and hypertension followed the same trend, although differences were not statistically different. 
There were also marked differences between variant groups regarding severity of disease at ICU admission. Indeed, patients infected with preexisting variants exhibited significantly higher severity of illness scores, with not only more severe respiratory disease, as assessed by the respiratory component of the SOFA score, but also more frequent extra-pulmonary organ failures, as compared with patients infected with variant a (B.1.1.7) and other emerging variants (Table 1 and Figure 2). As a result, patients infected with pre-existing variants received less frequent highflow oxygen therapy and more frequent extracorporeal membrane oxygenation (ECMO) support than other patients within the first 24 hours of ICU admission, while they more frequently met the ARDS definition criteria.

\section{Relationship between SARS-CoV-2 variants and patient outcomes}

Although patients infected with pre-existing variants were older, had more comorbidities and had more severe diseases at ICU admission, they did not show different outcomes from those infected with other variants. Overall, the need for invasive mechanical ventilation or ECMO support did not significantly differ between the different variant groups, nor did the duration of these supports. There were also no significant differences between groups regarding extra-pulmonary organ supports (i.e., vasopressors and renal replacement therapy) during ICU stay (Table

2). Patients with pre-existing variants received less dexamethasone and tocilizumab than others, likely reflecting the changes in practice during the study period. As shown in Table 2, day-28 and day-90 mortality rates were not statistically different between groups.

\section{Relationship between SARS-CoV-2 Spike substitutions and deletions and mortality}

Pre-existing and emerging variants (VOC or VOI) are characterized by multiple lineage-specific deletions and aminoacid substitutions. Spike mutations undergo evolutive convergence at several signature sites. Spike mutations at sites identified to undergo convergent mutational evolution were selected a priori. There was no significant relationship between any of these mutations $(n=17)$ and day-28 mortality in univariate analysis (Figure 3$)$. The selected mutations were also included in multivariate logistic regression models to determine their relationship with day-28 (Table 3) and day-90 (Supplemental Table 1) mortality, adjusting on age, gender, SOFA score at ICU admission, and dexamethasone treatment. None of them was significantly associated with mortality at either time point. The variant status was not either associated with mortality.

\section{Relationship between SARS-CoV-2 spike and other gene mutation hotspots and mortality}

Overall, 1017 non-synonymous mutations (including 953 amino acid substitutions, 52 deletions and 11 insertions) were detected in full-length viral genomes in at least one variant. There was no significant relationship between any of these mutations and day-28 mortality in univariate analysis (Supplemental Table 2). Although 11 mutations were found to be associated with mortality $(p<0.05)$, the number of patients harboring these mutations was considered too small (range: 2-6) to drive conclusions.

We then focused on mutations previously reported to correlate with worse clinical outcomes $[2,4,17]$. We found that Q57H in Orf3a (but not other mutations, including P25L in Orf3a and S194L, R203K or G204R in N) was highly prevalent in our cohort (31.8\%). Q57H was more prevalent in patients who were dead at day-28 (35.6\%) than in those who were still alive, but the difference did not reach significance $(29.0 \% ; p=0.196)$.

\section{Discussion}

The full-length SARS-CoV-2 genomes of 413 critically ill COVID-19 patients from 11 ICUs, who were predominantly infected with pre-existing and a (B.1.1.7) variants, were sequenced and the relationship between viral sequences and 
their clinical presentation and outcomes was studied. The main results of this study are the following: (i) as compared with others, patients infected with pre-existing variants showed a different clinical phenotype at ICU admission, characterized by an older age, more comorbidities and a more severe clinical presentation; (ii) despite these different initial clinical presentations, there were no significant differences in day-28 and day-90 mortality between the different SARS-CoV-2 variant groups; (iii) there was no statistically significant relationship between the presence of any of 17 relevant spike substitutions and deletions selected a priori and mortality; and (iv) a comprehensive full-length SARS-CoV-2 genome sequence analysis exploring all found mutations failed to identify a relationship between the presence of any of them and day-28 mortality.

Patients infected with variants pre-existing the emergence of variant a at the end of 2020 showed significant clinical differences, including an older age and more comorbidities, when compared with patients infected with other variants, in particular variant a (B.1.1.7), a result in keeping with those from previous cohorts [8-10]. Importantly, our results show differences in clinical severity of the disease resulting in different organ support requirements during the first 24 hours of management in the ICU in patients infected with different SARS-CoV-2 variants. Indeed, patients infected with pre-existing variants exhibited more severe pulmonary and non-pulmonary organ failures than those infected with variant a (B.1.1.7). Surprisingly, although admission severity of illness scores (i.e., SAPS II [15] and SOFA [14]) predicted higher mortality in patients infected with pre-existing variants, there was no significant difference in mortality rates when compared to patients infected with variant a (B.1.1.7). This finding, together with the fact that patients infected with variant a (B.1.1.7) reached similar organ support requirements during their ICU stay (Table 2), indicates that the severity of disease and the time course of organ failures have been delayed in patients infected with variant $a$, as compared to patients infected with pre-existing variants. Whether this different time course should be ascribed to host-related factors (e.g., age, comorbidities), a different pathogenesis/virulence of the variant, or differences in the type of patient management is unclear. Previous largescale data have suggested that patients infected with variant a (B.1.1.7), identified using the SGTF proxy, had a higher risk of dying $[6,9,10]$. However, in the study by Frampton et al., which included 341 hospitalized patients, no association was found between the severity of the disease, death and the viral lineage [8]. Interestingly, following SARS-CoV-2-infected patients with different disease severities through the pathway of disease management, Grint et al. reported a weakening association between variant a (B.1.1.7) infection and mortality, highest in the primary care population, lower in the hospitalized population, non-significant in patients admitted in the ICU [10]. Indeed, other determinants of COVID-19 mortality, including male gender, age, and associated comorbidities have been shown to have a major impact on the outcome [18]. Our results are thus not in contradiction with previous studies showing an increased mortality associated with variant a (B.1.1.7) in the community $[6,9]$. They are in keeping with data specific to ICU patient populations $[9,10]$.

Spike mutations have dominated SARS-CoV-2 variant research, owing to concerns regarding enhancement of viral replication and transmission via ACE-2 receptor binding and/or lower sensitivity to the action of naturally or vaccineinduced neutralizing antibodies. In contrast, little attention has been paid to variant-specific mutations in other viral proteins. Nevertheless, such mutations could be associated with different clinical outcomes. Previous large-scale studies based on the GISAID database and in vitro experiments suggested that amino acid substitutions in the $\mathrm{N}$ and Orf3a regions could be associated with more severe disease. To study the potential link between SARS-CoV-2 genetic diversity outside of the spike protein and severe COVID-19 cases outcomes, we analyzed all nonsynonymous mutations in the full-length SARS-CoV-2 genomes and not only assessed the relationship between variant status and mortality, as already performed by others [6,8-10], but also performed a mutational analysis of all viral genes. None of the pre-selected relevant spike substitutions/deletions ended up being associated with mortality, either in univariate or in multivariate analyses. When extending the analysis to all viral genes, we found 11 
mutations that were harbored by a very small number of patients $(n \leq 6)$ with a statistically significant difference but without clinically relevant meaning. Together, our results indicate that in patients with the most severe forms of COVID-19 who required ICU admission, there was no mutational pattern associated with mortality.

\section{Limitations and strengths of the study}

We acknowledge that our study has several limitations. The number of patients included was limited and thus the statistical power may have been too weak to show some between-group differences. Yet, there was no clear trend regarding associations between variant groups/mutations and mortality, suggesting that increasing the number of patients in the cohort would not have changed the results. Changes in management practices occurred during the study period, with more patients infected with variant a (B.1.1.7) and other variant groups receiving dexamethasone, with a possible impact on mortality [19]. Such bias was thus accounted for in the multivariate analysis. Additionally, the period of inclusion of the present study was October 1, 2020, which corresponded in France to the beginning of the second COVID-19 wave, a period when ICU admission policies, ICU patient load and demand, and COVID-19 management strategies were more homogeneous among centres than during the first COVID-19 wave.

Our study also has strengths, including the constitution of a prospective multicenter cohort of well-phenotyped critically ill patients, and the fact that we performed full-length SARS-CoV-2 genome sequencing by means of up-todate technology.

\section{Conclusions}

Patients with pre-existing variants had a different clinical presentation from patients infected with variant a (B.1.1.7) and other variants at ICU admission, characterized by an older age, more comorbidities and a more severe clinical presentation. However, there were no day-28 and day-90 mortality differences between the different groups. We found no association between the variant status or any mutational pattern in SARS-CoV-2 viral genes and mortality.

\section{Abbreviations}

ARDS, acute respiratory distress syndrome

ECMO, extracorporeal membrane oxygenation

ICU, intensive care unit

RT-PCR, reverse transcriptase-polymerase chain reaction

SAPS II, simplified acute physiology score

SGTF, S-gene molecular diagnostic assay failure

SOFA, sequential organ failure assessment

VOC, variants of concern

VOI, variants of interest

WHO, World Health Organization 


\section{Declarations}

Ethics approval and consent to participate: The study was approved by the Comité de Protection des Personnes Nord-Ouest IV ( $N^{\circ}$ EudraCT/ID-RCB : 2020-A03009-30). Informed consent was obtained from all patients or their relatives.

\section{Consent for publication: not applicable}

Availability of data and materials: all data generated and analyzed during this study are available on demand.

Competing interests: C.-E. L. has served as consultant for Bayer Healthcare, Carmat and Thermo Fisher Brahms, and received lecture fees from MSD, Aerogen, Advanzpharma and BioMérieux, outside the submitted work. Other authors have no conflict of interest to disclose.

Funding: This research received funding from the Agence Nationale de la Recherche (ANR-21-COVR-0022)

Author's contributions: Concept and design: Fourati, Pawlotsky, de Prost; Acquisition, analysis, or interpretation of data: All authors; Drafting of the manuscript: Fourati, de Prost; Critical revision of the manuscript for important intellectual content: All authors; Statistical analysis: Audureau; Obtained funding: de Prost; Administrative, technical, or material support: Fourati, Rodriguez, Audureau, de Prost; Supervision: Fourati, de Prost

Acknowledgements: The authors wish to thank the patients involved in the study and all the nurses and physicians involved in patient care in the intensive care units;

\section{References}

1. Martin DP, Weaver S, Tegally H, San JE, Shank SD, Wilkinson E, et al. The emergence and ongoing convergent evolution of the SARS-CoV-2 N501Y lineages. Cell. 2021;184:5189-5200.e7.

2. Majumdar P, Niyogi S. ORF3a mutation associated with higher mortality rate in SARS-CoV-2 infection. Epidemiol Infect. 2020;148:e262.

3. Young BE, Fong S-W, Chan Y-H, Mak T-M, Ang LW, Anderson DE, et al. Effects of a major deletion in the SARSCoV-2 genome on the severity of infection and the inflammatory response: an observational cohort study. Lancet. 2020;396:603-11.

4. Nagy Á, Pongor S, Győrffy B. Different mutations in SARS-CoV-2 associate with severe and mild outcome. Int J Antimicrob Agents. 2021;57:106272.

5. Abdelnabi R, Boudewijns R, Foo CS, Seldeslachts L, Sanchez-Felipe L, Zhang X, et al. Comparing infectivity and virulence of emerging SARS-CoV-2 variants in Syrian hamsters. EBioMedicine. 2021;68:103403.

6. Davies NG, Jarvis Cl, CMMID COVID-19 Working Group, Edmunds WJ, Jewell NP, Diaz-Ordaz K, et al. Increased mortality in community-tested cases of SARS-CoV-2 lineage B.1.1.7. Nature. 2021;593:270-4.

7. Giles B, Meredith P, Robson S, Smith G, Chauhan A, PACIFIC-19 and COG-UK research groups. The SARS-CoV-2 B.1.1.7 variant and increased clinical severity-the jury is out. Lancet Infect Dis. 2021;21:1213-4.

8. Frampton D, Rampling T, Cross A, Bailey H, Heaney J, Byott M, et al. Genomic characteristics and clinical effect of the emergent SARS-CoV-2 B.1.1.7 lineage in London, UK: a whole-genome sequencing and hospital-based cohort study. Lancet Infect Dis. 2021;21:1246-56. 
9. Patone M, Thomas K, Hatch R, Tan PS, Coupland C, Liao W, et al. Mortality and critical care unit admission associated with the SARS-CoV-2 lineage B.1.1.7 in England: an observational cohort study. Lancet Infect Dis. 2021;21:1518-28.

10. Grint DJ, Wing K, Houlihan C, Gibbs HP, Evans SJW, Williamson E, et al. Severity of SARS-CoV-2 alpha variant (B.1.1.7) in England. Clin Infect Dis. 2021;ciab754.

11. Lee HK, Knabl L, Knabl L, Wieser M, Mur A, Zabernigg A, et al. Immune transcriptomes from hospitalized patients infected with the SARS-CoV-2 variants B.1.1.7 and B.1.1.7 carrying the E484K escape mutation. medRxiv. 2021;2021.05.27.21257952.

12. Rockwood K, Song X, MacKnight C, Bergman H, Hogan DB, McDowell I, et al. A global clinical measure of fitness and frailty in elderly people. CMAJ. 2005;173:489-95.

13. WHO Working Group on the Clinical Characterisation and Management of COVID-19 infection. A minimal common outcome measure set for COVID-19 clinical research. Lancet Infect Dis. 2020;20:e192-7.

14. Vincent JL, Moreno R, Takala J, Willatts S, De Mendonça A, Bruining H, et al. The SOFA (Sepsis-related Organ Failure Assessment) score to describe organ dysfunction/failure. On behalf of the Working Group on SepsisRelated Problems of the European Society of Intensive Care Medicine. Intensive Care Med. 1996;22:707-10.

15. Le Gall JR, Lemeshow S, Saulnier F. A new Simplified Acute Physiology Score (SAPS II) based on a European/North American multicenter study. JAMA. 1993;270:2957-63.

16. ARDS Definition Task Force, Ranieri VM, Rubenfeld GD, Thompson BT, Ferguson ND, Caldwell E, et al. Acute respiratory distress syndrome: the Berlin Definition. JAMA. 2012;307:2526-33.

17. Pang X, Li P, Zhang L, Que L, Dong M, Xie B, et al. Emerging Severe Acute Respiratory Syndrome Coronavirus 2 Mutation Hotspots Associated With Clinical Outcomes and Transmission. Front Microbiol. 2021;12:753823.

18. Williamson EJ, Walker AJ, Bhaskaran K, Bacon S, Bates C, Morton CE, et al. Factors associated with COVID-19related death using OpenSAFELY. Nature. 2020;584:430-6.

19. RECOVERY Collaborative Group, Horby P, Lim WS, Emberson JR, Mafham M, Bell JL, et al. Dexamethasone in Hospitalized Patients with Covid-19. N Engl J Med. 2021;384:693-704.

\section{Tables}

Table 1. Characteristics of the 413 patients with severe SARS-CoV-2 infection at the time of intensive care unit admission, according to their infecting SARS-CoV-2 variant. 


\begin{tabular}{|c|c|c|c|c|c|c|}
\hline $\begin{array}{l}\text { Pre- } \\
\text { existing } \\
\text { variants }\end{array}$ & $\begin{array}{c}\text { Variant a } \\
(\text { B.1.1.7) }\end{array}$ & $\begin{array}{l}\text { Other } \\
\text { variants }\end{array}$ & p-values & & & \\
\hline$N=183$ & $N=197$ & $N=33$ & $\begin{array}{l}\text { Global } \\
\text { comparison }\end{array}$ & $\begin{array}{l}\text { Pre- } \\
\text { existing } \\
\text { vs. } a^{a}\end{array}$ & $\begin{array}{l}\text { Pre- } \\
\text { existing } \\
\text { vs. } \\
\text { Others }\end{array}$ & $\begin{array}{l}a v s . \\
\text { Others }^{a}\end{array}$ \\
\hline
\end{tabular}

\section{Demographics \\ and comorbidities}

\begin{tabular}{|c|c|c|c|c|c|c|c|}
\hline Gender, males & $\begin{array}{l}124 \\
(67.8 \%)\end{array}$ & $\begin{array}{l}140 \\
(71.1 \%)\end{array}$ & $18(54.5 \%)$ & 0.165 & - & - & - \\
\hline Age, years & $\begin{array}{l}65.0 \\
( \pm 11.9)\end{array}$ & $\begin{array}{l}60.5 \\
( \pm 11.8)\end{array}$ & $\begin{array}{l}62.2 \\
( \pm 10.7)\end{array}$ & 0.001 & 0.001 & 0.531 & 0.823 \\
\hline Diabetes & 67 (36.6\%) & 59 (29.9\%) & 7 (21.2\%) & 0.141 & - & - & - \\
\hline Hypertension & $\begin{array}{l}108 \\
(59.0 \%)\end{array}$ & $98(49.7 \%)$ & $16(48.5 \%)$ & 0.159 & - & - & - \\
\hline $\begin{array}{l}\text { Peripheral } \\
\text { vascular disease }\end{array}$ & $28(15.3 \%)$ & 19 (9.6\%) & $1(3.0 \%)$ & 0.075 & - & - & - \\
\hline $\begin{array}{l}\text { Chronic heart } \\
\text { failure }\end{array}$ & 19 (10.4\%) & $20(10.2 \%)$ & $2(6.1 \%)$ & 0.851 & - & - & - \\
\hline $\begin{array}{l}\text { Chronic kidney } \\
\text { disease }\end{array}$ & $34(18.6 \%)$ & $23(11.7 \%)$ & $1(3.0 \%)$ & 0.025 & 0.178 & 0.063 & 0.517 \\
\hline Cirrhosis & $3(1.6 \%)$ & $4(2.0 \%)$ & $0(0.0 \%)$ & 1.000 & - & - & - \\
\hline Cancer & $15(8.2 \%)$ & $8(4.1 \%)$ & $1(3.0 \%)$ & 0.180 & - & - & - \\
\hline HIV infection & $1(0.5 \%)$ & $3(1.5 \%)$ & $1(3.0 \%)$ & 0.274 & - & - & - \\
\hline Corticosteroids & $14(7.7 \%)$ & $9(4.6 \%)$ & $1(3.0 \%)$ & 0.445 & - & - & - \\
\hline COPD & 21 (11.5\%) & $8(4.1 \%)$ & $2(6.1 \%)$ & 0.021 & 0.021 & 0.904 & 0.953 \\
\hline Tobacco & 26 (14.2\%) & 23 (11.7\%) & $4(12.1 \%)$ & 0.769 & - & - & - \\
\hline $\mathrm{BMI}, \mathrm{kg} / \mathrm{m}^{2}$ & $30.2( \pm 6.8)$ & $29.8( \pm 6.6)$ & $30.2( \pm 6.0)$ & 0.857 & - & - & - \\
\hline $\begin{array}{l}\text { Clinical frailty } \\
\text { scale }\end{array}$ & $\begin{array}{l}3.0 \\
(2.0 ; 4.0)\end{array}$ & $\begin{array}{l}3.0 \\
(2.0 ; 4.0)\end{array}$ & $\begin{array}{l}3.0 \\
(2.0 ; 3.0)\end{array}$ & 0.069 & - & - & - \\
\hline
\end{tabular}

Disease severity upon ICU admission and biological features

\begin{tabular}{|c|c|c|c|c|c|c|c|}
\hline $\begin{array}{l}\text { WHO 10-point } \\
\text { scale }\end{array}$ & $6(6 ; 8)$ & $6(6 ; 8)$ & $6(6 ; 8)$ & 0.114 & - & - & - \\
\hline SAPS II score & $37(30 ; 50)$ & $30(24 ; 40)$ & $32(24 ; 41)$ & 0.000 & 0.000 & 0.025 & 0.971 \\
\hline SOFA score & $4(3 ; 8)$ & $3(2 ; 4)$ & $4(2 ; 4)$ & 0.000 & 0.000 & 0.156 & 0.935 \\
\hline $\begin{array}{l}\text { Blood } \\
\text { neutrophils, G/L }\end{array}$ & $\begin{array}{l}7.9 \\
(5.3 ; 11.3)\end{array}$ & $\begin{array}{l}6.3 \\
(4.6 ; 9.1)\end{array}$ & $\begin{array}{l}8.7 \\
(5.8 ; 12.2)\end{array}$ & 0.006 & 0.017 & 0.737 & 0.061 \\
\hline Blood & 0.6 & 0.7 & $\begin{array}{l}0.8 \\
\text { Page 11/17 }\end{array}$ & 0.217 & - & - & - \\
\hline
\end{tabular}




\begin{tabular}{|c|c|c|c|c|c|c|c|}
\hline lymphocytes, G/L & $(0.4 ; 0.9)$ & $(0.4 ; 0.8)$ & $(0.6 ; 1.0)$ & & & & \\
\hline $\begin{array}{l}\text { Blood urea level, } \\
\text { mM }\end{array}$ & $\begin{array}{l}8.4 \\
(6.0 ; 12.5)\end{array}$ & $\begin{array}{l}6.5 \\
(4.9 ; 10.2)\end{array}$ & $\begin{array}{l}6.3 \\
(5.5 ; 8.7)\end{array}$ & 0.000 & 0.000 & 0.038 & 0.999 \\
\hline D-dimers, ng/mL & $\begin{array}{l}1441 \\
(771 ; 2614)\end{array}$ & $\begin{array}{l}1310 \\
(931 ; 2183)\end{array}$ & $\begin{array}{l}1300 \\
(799 ; 2030)\end{array}$ & 0.917 & - & - & - \\
\hline $\begin{array}{l}\text { Bacterial } \\
\text { coinfection }\end{array}$ & $25(13.7 \%)$ & $22(11.2 \%)$ & $2(6.1 \%)$ & 0.494 & - & - & - \\
\hline
\end{tabular}

\section{Organ supports and management during the first 24 hours $^{b}$}

\begin{tabular}{|c|c|c|c|c|c|c|c|}
\hline Oxygen & $5(2.7 \%)$ & $6(3.0 \%)$ & $4(12.1 \%)$ & 0.045 & 1.000 & 0.095 & 0.114 \\
\hline High flow oxygen & $\begin{array}{l}105 \\
(57.4 \%)\end{array}$ & $\begin{array}{l}140 \\
(71.1 \%)\end{array}$ & $23(69.7 \%)$ & 0.017 & 0.016 & 0.458 & 0.998 \\
\hline NIV/C-PAP & $55(30.1 \%)$ & $51(25.9 \%)$ & 12 (36.4\%) & 0.392 & - & - & - \\
\hline Invasive MV & $88(48.1 \%)$ & 78 (39.6\%) & $12(36.4 \%)$ & 0.178 & - & - & - \\
\hline Prone position & $79(43.2 \%)$ & $92(46.7 \%)$ & $15(45.5 \%)$ & 0.786 & - & - & - \\
\hline ECMO & $24(13.1 \%)$ & $9(4.6 \%)$ & $3(9.1 \%)$ & 0.010 & 0.010 & 0.989 & 0.770 \\
\hline ARDS criteria & $\begin{array}{l}147 \\
(80.3 \%)\end{array}$ & $\begin{array}{l}136 \\
(69.0 \%)\end{array}$ & $21(63.6 \%)$ & 0.018 & 0.035 & 0.098 & 0.901 \\
\hline Vasopressors & 35 (19.1\%) & $34(17.3 \%)$ & $4(12.1 \%)$ & 0.654 & - & - & - \\
\hline Antibiotics & $\begin{array}{l}123 \\
(67.2 \%)\end{array}$ & $\begin{array}{l}115 \\
(58.4 \%)\end{array}$ & $19(57.6 \%)$ & 0.175 & - & - & - \\
\hline
\end{tabular}

apairwise comparisons applying a Sidak correction to account for multiple testing; ${ }^{\text {}}$ More than one type of respiratory support may have been used per patient during the first 24 hours. Thus the total may be more than $100 \%$.

COPD : chronic obstructive pulmonary disease ; BMI : body masse index ; SAPS : simplified acute physiology score ; SOFA : sequential organ failure assessment; NIV: non-invasive ventilation; C-PAP: continuous-positive airway pressure; MV: mechanical ventilation; ECMO: extracorporeal membrane oxygenation; ARDS: acute respiratory distress syndrome

Table 2. Outcomes of the 413 patients with severe SARS-CoV-2 infection during intensive care unit stay, according to their infecting SARS-CoV-2 variant. 


\begin{tabular}{lllllll}
$\begin{array}{l}\text { Preexisting } \\
\text { variants }\end{array}$ & $\begin{array}{l}\text { Variant } \\
\mathbf{a}(\mathrm{B} .1 .1 .7)\end{array}$ & $\begin{array}{l}\text { Other } \\
\text { variants }\end{array}$ & p-values & & \\
\\
$\mathrm{N}=183$ & $\mathrm{~N}=197$ & $\mathrm{~N}=33$ & $\begin{array}{l}\text { Global } \\
\text { comparison }\end{array}$ & $\begin{array}{l}\text { Preexisting } \\
\text { vs. } a^{a}\end{array}$ & $\begin{array}{l}\text { Preexisting } \\
\text { vs. others }\end{array}$ & $\begin{array}{l}\text { a vs. } \\
\text { others }\end{array}$ \\
\hline
\end{tabular}

\begin{tabular}{|c|c|c|c|c|c|c|c|}
\hline Invasive MV & $\begin{array}{l}125 \\
(68.3 \%)\end{array}$ & $\begin{array}{l}120 \\
(60.9 \%)\end{array}$ & $\begin{array}{l}22 \\
(66.7 \%)\end{array}$ & 0,312 & - & - & - \\
\hline $\begin{array}{l}\text { MV duration, } \\
\text { days }\end{array}$ & $16(9 ; 27)$ & $14(8 ; 23)$ & $\begin{array}{l}16.5 \\
(10 ; 30)\end{array}$ & 0.362 & - & - & - \\
\hline ECMO support & $29(15.8 \%)$ & $19(9.6 \%)$ & $6(18.2 \%)$ & 0.133 & - & - & - \\
\hline $\begin{array}{l}\text { Duration of } \\
\text { ECMO, days }\end{array}$ & $\begin{array}{l}17.0 \\
(6.0 ; 31.0)\end{array}$ & $\begin{array}{l}12.0 \\
(4.0 ; 17.0)\end{array}$ & $\begin{array}{l}34.5 \\
(8.0 ; 55.0)\end{array}$ & 0.186 & - & - & - \\
\hline $\begin{array}{l}\text { Vasopressor } \\
\text { support }\end{array}$ & 87 (47.5\%) & $\begin{array}{l}94 \\
(47.7 \%)\end{array}$ & $\begin{array}{l}17 \\
(51.5 \%)\end{array}$ & 0.912 & - & - & - \\
\hline $\begin{array}{l}\text { Duration of } \\
\text { vasopressors, } \\
\text { days }\end{array}$ & $7(3 ; 15)$ & $9(4 ; 16)$ & $9(3 ; 14)$ & 0.862 & - & - & - \\
\hline RRT & $47(25.7 \%)$ & $\begin{array}{l}53 \\
(26.9 \%)\end{array}$ & $7(21.2 \%)$ & 0.784 & - & - & - \\
\hline $\begin{array}{l}\text { Pulmonary } \\
\text { thrombosis }\end{array}$ & $10(5.5 \%)$ & $11(5.6 \%)$ & $1(3.0 \%)$ & 1.000 & - & - & - \\
\hline VAP & $88(48.1 \%)$ & $\begin{array}{l}85 \\
(43.4 \%)\end{array}$ & $\begin{array}{l}15 \\
(45.5 \%)\end{array}$ & 0.654 & - & - & - \\
\hline Dexamethasone & $\begin{array}{l}143 \\
(78.1 \%)\end{array}$ & $\begin{array}{l}168 \\
(85.3 \%)\end{array}$ & $\begin{array}{l}31 \\
(93.9 \%)\end{array}$ & 0.038 & 0.199 & 0.101 & 0.444 \\
\hline Tocilizumab & $6(3.3 \%)$ & $\begin{array}{l}25 \\
(12.7 \%)\end{array}$ & $4(12.1 \%)$ & 0.002 & 0.003 & 0.139 & 1.000 \\
\hline $\begin{array}{l}\text { Day-28 } \\
\text { mortality }\end{array}$ & 57 (31.1\%) & $\begin{array}{l}51 \\
(26.2 \%)\end{array}$ & $\begin{array}{l}10 \\
(30.3 \%)\end{array}$ & 0.550 & - & - & - \\
\hline $\begin{array}{l}\text { Day-90 } \\
\text { mortality }\end{array}$ & 74 (40.4\%) & $\begin{array}{l}61 \\
(31.6 \%)\end{array}$ & $\begin{array}{l}13 \\
(39.4 \%)\end{array}$ & 0.189 & - & - & - \\
\hline
\end{tabular}

aPairwise comparisons applying a Sidak correction to account for multiple testing.

MV: mechanical ventilation; ECMO: extracorporeal membrane oxygenation; RRT: renal replacement therapy; VAP: ventilator-acquired pneumonia

Table 3. Relationship between SARS-CoV-2 variants, spike mutations [(substitutions or deletions (Del)] selected a priori and day-28 mortality by multivariate logistic regression analysis. 


\begin{tabular}{|c|c|c|c|c|c|c|}
\hline & & All patients & $\begin{array}{l}\text { Day-28 } \\
\text { survivors }\end{array}$ & $\begin{array}{l}\text { Day-28 } \\
\text { non- } \\
\text { survivors }\end{array}$ & $\mathrm{ORa}^{\mathrm{a}}$ (Cl95\%) & $\begin{array}{l}\mathrm{p}- \\
\text { value }\end{array}$ \\
\hline & & $N=411$ & $N=293$ & $\mathrm{~N}=118$ & & \\
\hline Variants & $a$ & $\begin{array}{l}195 \\
(47.4 \%)\end{array}$ & $144(49.1 \%)$ & $51(43.2 \%)$ & 1 (ref) & 0.347 \\
\hline & $\begin{array}{l}\text { Pre-existing } \\
\text { variant }\end{array}$ & $\begin{array}{l}183 \\
(44.5 \%)\end{array}$ & $126(43.0 \%)$ & $57(48.3 \%)$ & $0.75(0.45 ; 1.25)$ & 0.263 \\
\hline & Others & $33(8.0 \%)$ & $23(7.8 \%)$ & $10(8.5 \%)$ & $1.31(0.55 ; 3.13)$ & 0.549 \\
\hline N501Y & & $\begin{array}{l}220 \\
(53.5 \%)\end{array}$ & $162(55.3 \%)$ & $58(49.2 \%)$ & $1.29(0.80 ; 2.11)$ & 0.299 \\
\hline $\begin{array}{l}\text { N501Y } \\
\times a^{b}\end{array}$ & None & $\begin{array}{l}191 \\
(46.5 \%)\end{array}$ & 131 (44.7\%) & $60(50.8 \%)$ & 1 (ref) & 0.565 \\
\hline & N501Y & $25(6.1 \%)$ & $18(6.1 \%)$ & $7(5.9 \%)$ & $1.45(0.53 ; 3.97)$ & 0.473 \\
\hline & N501Y \& a & $\begin{array}{l}195 \\
(47.4 \%)\end{array}$ & 144 (49.1\%) & $51(43.2 \%)$ & $1.28(0.77 ; 2.11)$ & 0.342 \\
\hline Del 69-70 & & $\begin{array}{l}193 \\
(47.0 \%)\end{array}$ & $143(48.8 \%)$ & $50(42.4 \%)$ & $1.22(0.75 ; 1.98)$ & 0.426 \\
\hline $\begin{array}{l}\text { Del } 140- \\
145\end{array}$ & & $\begin{array}{l}195 \\
(47.4 \%)\end{array}$ & 145 (49.5\%) & $50(42.4 \%)$ & $1.20(0.74 ; 1.95)$ & 0.468 \\
\hline $\begin{array}{l}\text { Del 242- } \\
244\end{array}$ & & $20(4.9 \%)$ & $15(5.1 \%)$ & $5(4.2 \%)$ & $1.34(0.44 ; 4.09)$ & 0.607 \\
\hline L5F & & $16(3.9 \%)$ & $11(3.8 \%)$ & $5(4.2 \%)$ & $1.02(0.32 ; 3.27)$ & 0.978 \\
\hline L18F & & $17(4.1 \%)$ & $13(4.4 \%)$ & $4(3.4 \%)$ & $1.19(0.34 ; 4.10)$ & 0.788 \\
\hline D80A/G & & $20(4.9 \%)$ & $15(5.1 \%)$ & $5(4.2 \%)$ & $1.21(0.40 ; 3.66)$ & 0.733 \\
\hline S98F & & $13(3.2 \%)$ & $10(3.4 \%)$ & $3(2.5 \%)$ & $0.76(0.18 ; 3.17)$ & 0.703 \\
\hline K417N/T & & $22(5.4 \%)$ & $17(5.8 \%)$ & $5(4.2 \%)$ & $1.02(0.34 ; 3.02)$ & 0.976 \\
\hline L452R & & $8(1.9 \%)$ & $5(1.7 \%)$ & $3(2.5 \%)$ & $1.57(0.33 ; 7.41)$ & 0.569 \\
\hline S477N & & $76(18.5 \%)$ & 49 (16.7\%) & $27(22.9 \%)$ & $0.79(0.43 ; 1.45)$ & 0.447 \\
\hline E484K & & $25(6.1 \%)$ & $19(6.5 \%)$ & $6(5.1 \%)$ & $1.06(0.38 ; 2.94)$ & 0.908 \\
\hline A570D & & $\begin{array}{l}192 \\
(46.7 \%)\end{array}$ & 142 (48.5\%) & $50(42.4 \%)$ & $1.23(0.76 ; 2.00)$ & 0.406 \\
\hline D614G & & $\begin{array}{l}400 \\
(97.3 \%)\end{array}$ & 286 (97.6\%) & $114(96.6 \%)$ & $0.65(0.16 ; 2.68)$ & 0.550 \\
\hline H655Y & & $6(1.5 \%)$ & $4(1.4 \%)$ & $2(1.7 \%)$ & $1.07(0.17 ; 6.59)$ & 0.946 \\
\hline P681H & & $\begin{array}{l}190 \\
(46.2 \%)\end{array}$ & 140 (47.8\%) & $50(42.4 \%)$ & $1.29(0.79 ; 2.09)$ & 0.310 \\
\hline P681R & & $9(2.2 \%)$ & $5(1.7 \%)$ & $4(3.4 \%)$ & $\begin{array}{l}2.72 \\
(0.61 ; 12.05)\end{array}$ & 0.189 \\
\hline
\end{tabular}


${ }^{a}$ Multivariate analysis adjusted on age, SOFA score at admission, gender and dexamethasone treatment; ${ }^{b}$ This variable comes from the interaction of the variable « variant $\mathrm{a}$ » and the variable "N501Y mutation »; ORa : adjusted odds ratio ; $95 \% \mathrm{Cl}: 95 \%$ confidence interval

\section{Figures}

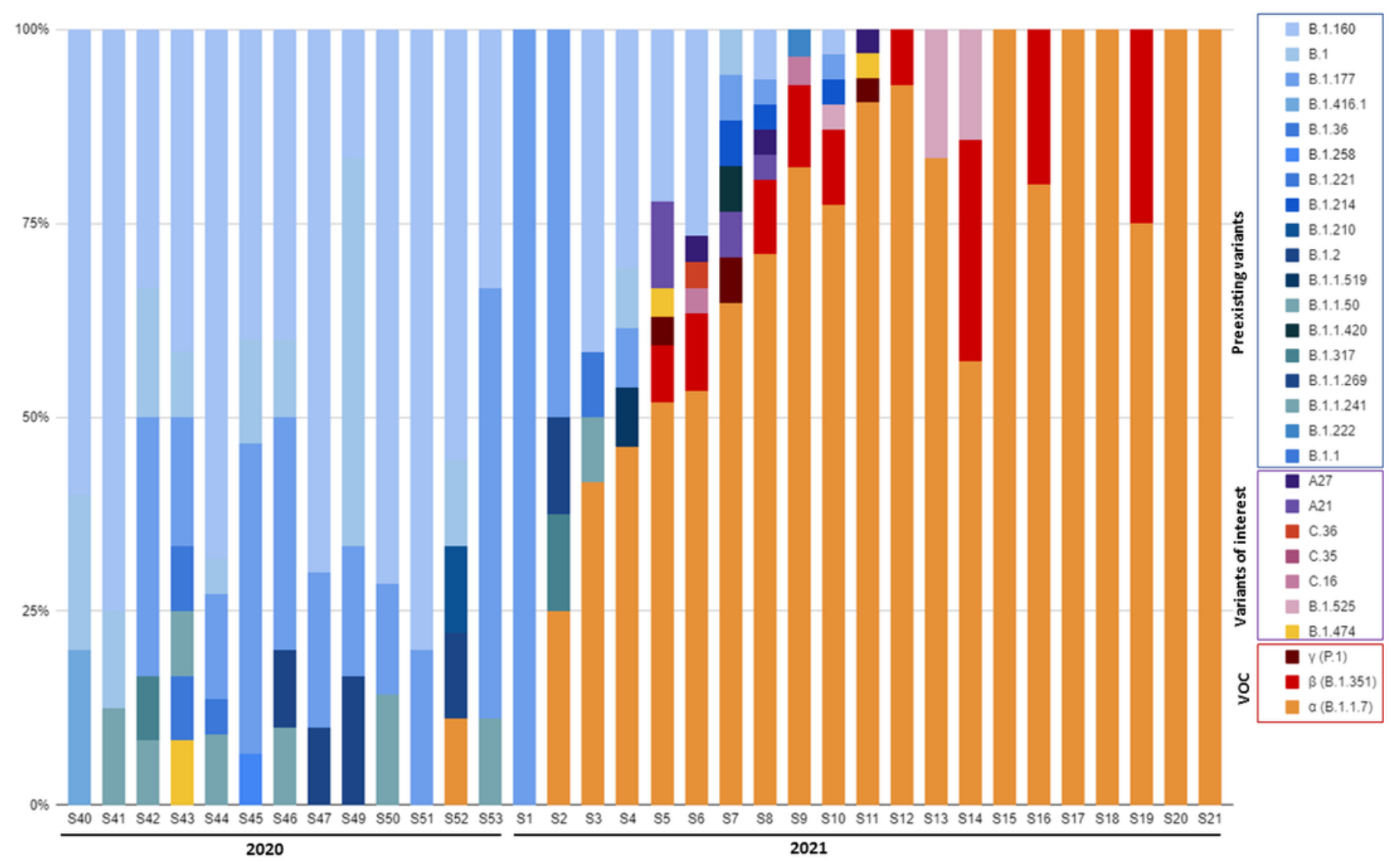

Figure 1

Time course of emerging SARS-CoV-2 variants during the study period. VOC, variants of concern. 


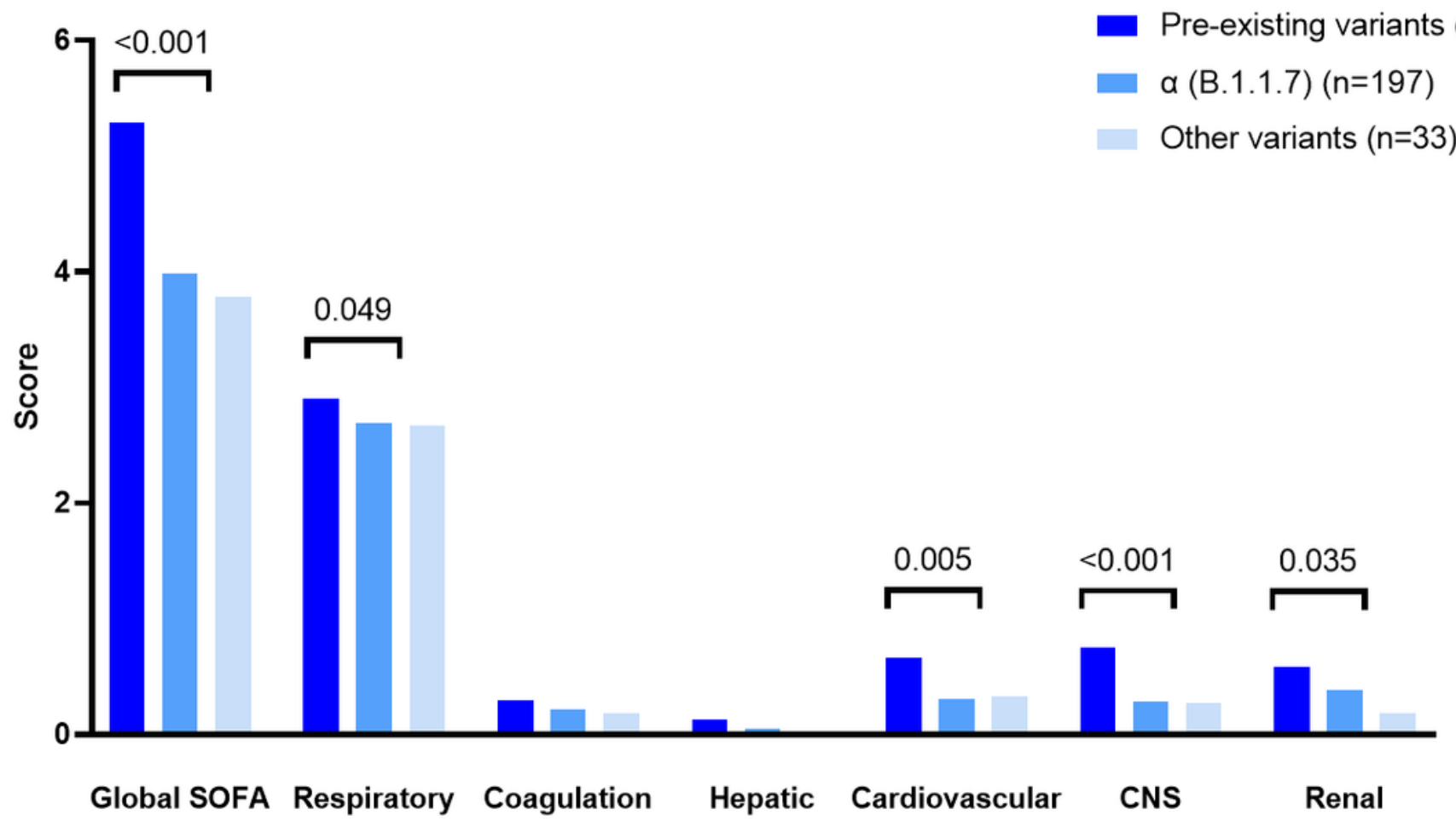

Figure 2

SOFA score and its organ system components in patients with the pre-existing, a (B.1.1.7) or other variants. P values come from ANOVA. 


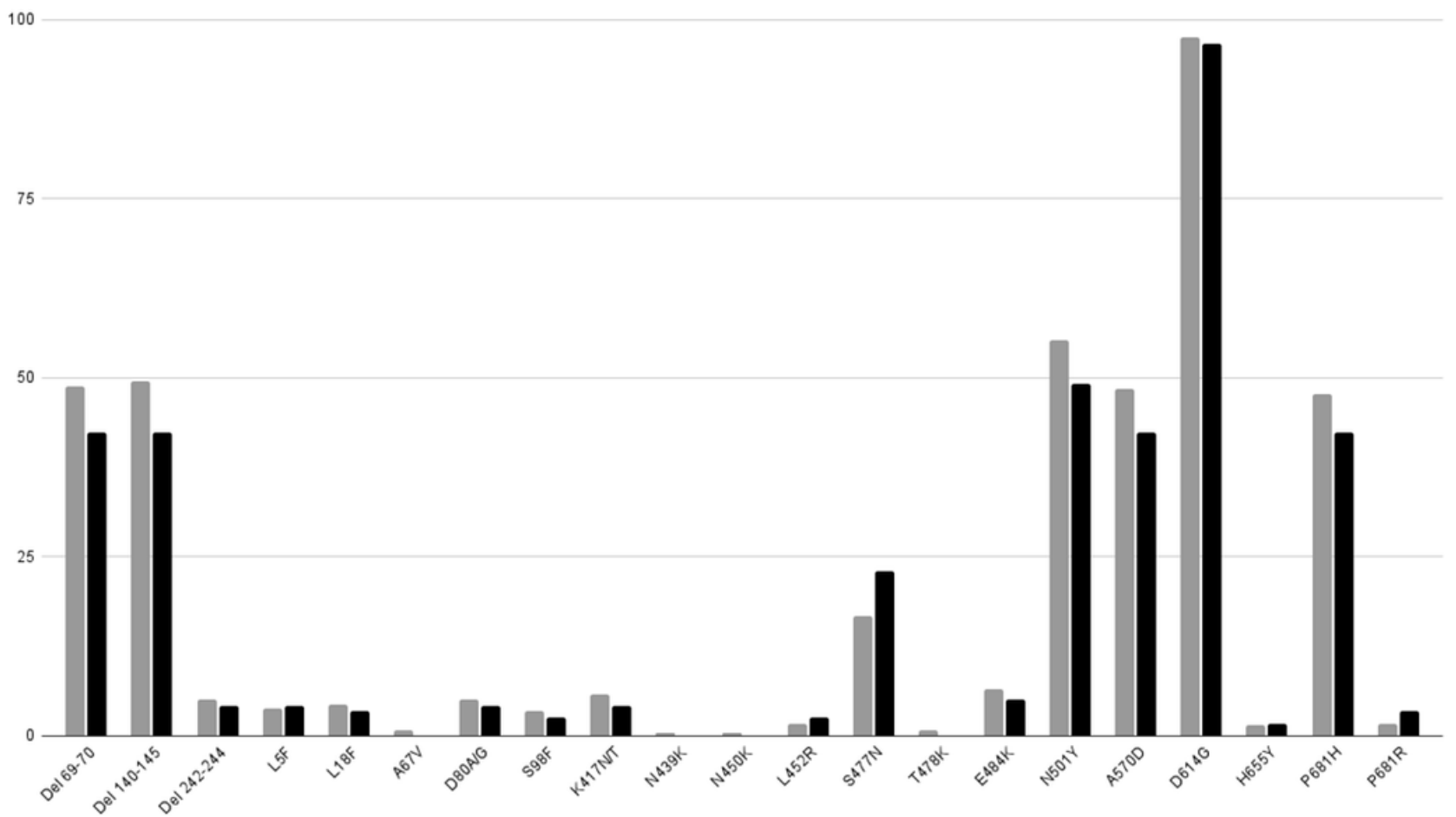

Figure 3

Frequency of preselected SARS-CoV-2 mutations in spike according to day-28 mortality status. There was no statistical difference for any of the comparisons performed (grey bars indicate survivors, black bars indicate decedents).

\section{Supplementary Files}

This is a list of supplementary files associated with this preprint. Click to download.

- AdditionalTable1.docx

- AdditionalTable2.docx 